\title{
Understanding triggering mechanisms of volcanoes for hazard evaluation
}

Current methods for short-term prediction of volcanic eruptions are based mainly on phenomenological correlations between preeruptive signals and the eruption itself. The results obtained on well-studied and well-monitored test volcanoes are of no general application, owing to their nontransferable peculiarities. Efforts in forecasting must be directed towards a better understanding of the physical and chemical processes triggering volcanic eruptions. (Ed.)

\section{Introduction}

$T_{\text {he title refers to one of the most urgent scientific problems in }}$ volcanic hazard evaluation. In spite of the efforts of many researchers, the triggering mechanisms of volcanic eruptions are poorly understood. Is the knowledge of these mechanisms relevant to mitigate the toll of lives and property of volcanic eruptions?

Before eruption, volcanoes often reveal their activity through gas emissions, ground deformations, seismic phenomena, and other effects. This activity can be observed by means of appropriate instruments. How should the information content of the observed activity be evaluated? In relation to the problem of forecasting eruption phases, two different approaches may be considered. The phenomenological one, a descriptive approach, consists of detecting possible correlations between preeruptive activity, the beginning of the eruption, and characteristics of the eruption phase. The alternative approach aims at the comprehension of the physical and chemical phenomena that trigger and control eruptions. From a systemtheoretical point of view, the phenomenological approach seems more appropriate to the aim of risk assessment. Nevertheless, different factors limit the achievement of practical results. The shortness of the observation period, the lack of information related to previous eruptions, and the difficulty to transfer acquired knowledge to other volcanoes are some of these factors. The application of methods of forecasting on the basis of the understanding of the processes triggering the eruptive phase requires an estimation of the volcano's internal behavior (the internal state) by means of the observed preeruptive activity. Compared with usual experiments, observation of the state of volcanoes has to be carried out under difficult (noisy) conditions. The phenomena that have to be explained cannot be sharply delimited, and basic parameters involved in the processes cannot be directly determined and are therefore only approximately known. Therefore, besides the desired information, the collected data contains contributions of phenomena whose cause and influence cannot be estimated. Owing to the complexity of these problems, efforts in short-term prediction of volcanic eruptions (that is, moment of the eruption onset and characteristics of the eruptive phase) are nowadays mainly based on phenomenological correlations. Nevertheless,

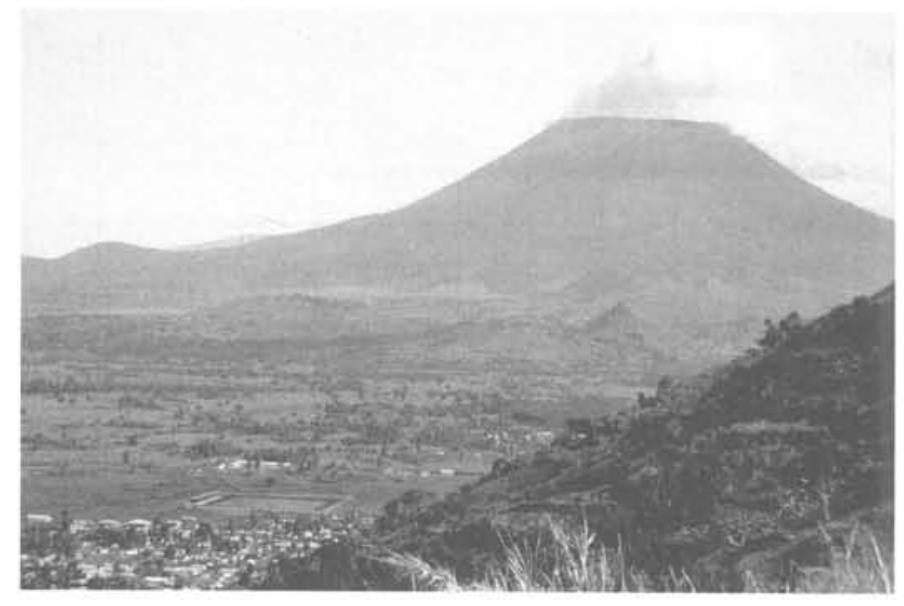

Figure 1.-Volcano Nyiragongo, Zaire, with the near town of Gisenyi, Rwanda.

the aims of this approach remain fuzzy and must be clarified. The question whether future main efforts to predict eruptions must be maintained in the descriptive domain or set on understanding triggering mechanisms on the basis of quantifiable observations of preeruptive activity, is not nearly as simple as one might think and needs to be carefully examined.

In the following sections the author, on the basis of personal experience from two eruptions-Nyiragongo, Zaire, 1977 and $\mathrm{Ne}$ vado del Ruiz, Colombia, 1985-emphasizes the need to improve the knowledge on triggering mechanisms in order to facilitate decisions in emergency management.

\section{Nyiragongo}

Mount Nyiragongo (fig. 1) belongs to the Virunga volcanic range, in the western branch of the East African rift system and is located on the eastern border of Zaire. Since its discovery by Stuhlmann in 1891 (Stuhlmann, 1894), no activity outside the crater was observed before January 10, 1977. Between (probably) 1928 and this last date, Nyiragongo showed molten lava activity inside the summit crater (at the inner pit). Since its first observation by Tazieff in 1948 (Tazieff, 1949), the lava lake had been exhibiting continuous and sometimes rapid level variations (fig. 2): more than $230 \mathrm{~m}$ between the observations in 1959 and 1976, while sometimes variations of a few meters occurred within only a few minutes (Tazieff, 1977). The mechanisms leading to a persistent lava-lake activity over years are not yet satisfactorily explained. The level variations however, may be viewed as a hydrostatic response to the pressure conditions of depth.

On January 10, 1977, Nyiragongo erupted (fig. 3). This eruption was exceptional (Tazieff, 1977) in the sense, that the molten 
material of the lake, as well as the magma of the feeding system were suddenly drained out and spread over a $20 \mathrm{~km}^{2}$ area through several simultaneously opening lateral outbreaks in the northwest (Baruta side) and southeast (Shaheru side) of the volcano. Due to the exceptionally high fluidity of the magma and to a high hydrostatic pressure between the altitude of the lava lake (about $3,270 \mathrm{~m}$ ), and that of the outbreaks (from 1,770 to $2,200 \mathrm{~m}$ ), the duration of the eruption was very short (less than half an hour). Through a fissure in the southeastern part, lava reached a populated area. Several villages were

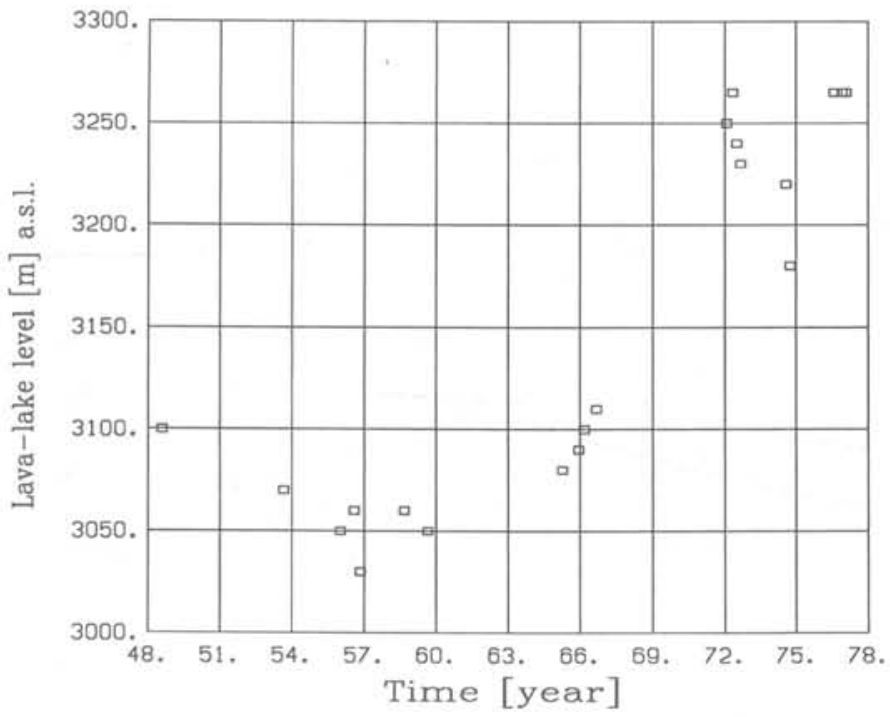

Figure 2.-Variation of the Nyiragongo magma-lake level from July 1948 to January 1977 (from Tazieff, 1977).

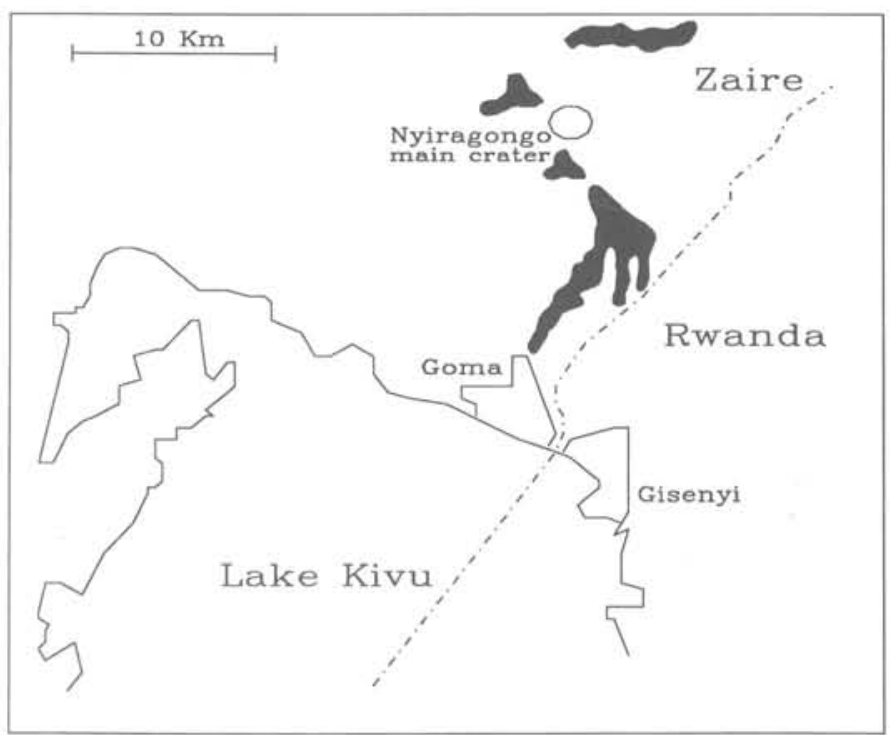

Figure 3.-Sketch map of the lava flows of the Nyiragongo January 10, 1977, eruption (after Hamaguchi and others, 1982). Dot-dashed line: country border. Black area: the surface affected by the flow of molten lava. Both the towns of Goma and Gisenyi, with more than 50,000 people, are located approximately $15 \mathrm{~km}$ to the south of the main crater. destroyed and over 1,000 people killed (Tazieff, 1985). Fortunately, an important part of the outcoming material was spread out over the forest to the north and to the west, thus sparing 50,000 people in Goma (fig. 4) major casualties. The eruption found the local population unprepared. A trip to the crater on January 5, showed the unusual level reached by the lava surface (fig. 5) and high degasing activity inside the lake itself. The exceptionally high level reached by the lava lake had been previously observed in 1972. At that time nothing happened, and therefore the high lake level was not regarded as a sign of danger. Furthermore, the volcano was not adequately monitored, and the few earthquakes felt by the population before the eruption are not unusual in that region.

Which mechanism triggered the eruption phase? Sahama (reported in Tazieff, 1985) suggested that magma rising through the feeding system may have induced a swelling large enough to split the mountain. The suggested swelling of the volcanic structure can hardly be considered a consequence of only the hydrostatic pressure exerted by the liquid column. In addition, a fast, unbalanced growth of the pressure at depth should be taken into account to explain the simultaneity of the occurrences of several lateral fissures. The pressure growth in the feeding system, not accommodated by a corre.

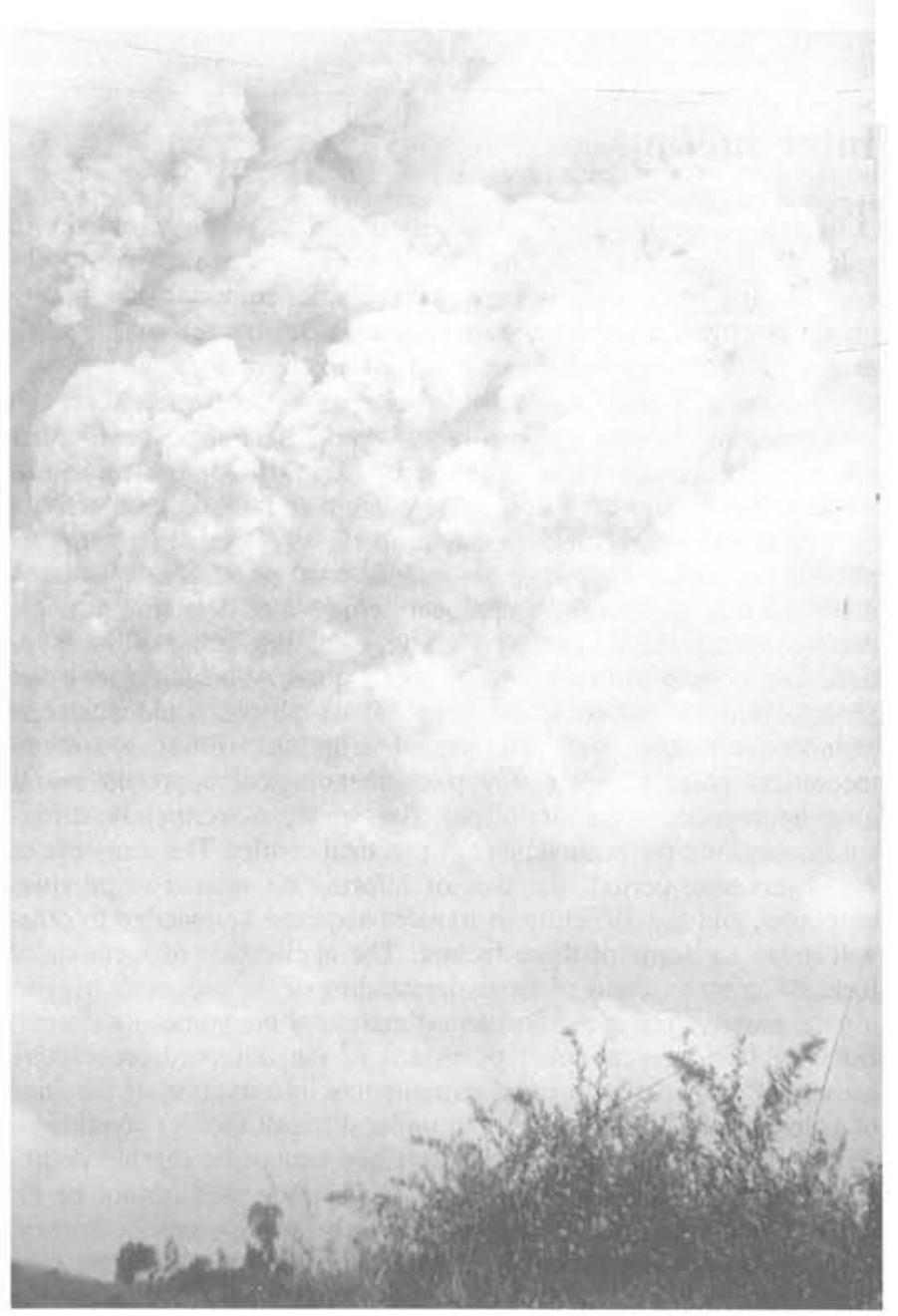

Figure 4.-Nyiragongo, Zaire. Eruption of January 10, 1977, about 5 minutes after it broke out, as seen from Gisenyi, $15 \mathrm{~km}$ to the south of the main crater. 
sponding increase of the lava-lake level, can be explained with the fact that the magma, owing to the presence of volatile components, did not have the opportunity to rise freely in the feeding system. For shallow regions (for example, less than $2,000 \mathrm{~m}$ depth), the presence of a free magmatic gas phase should be taken into consideration at a volcano like Nyiragongo (Sparks, 1978). Such a gas phase greatly reduces the propagation velocity of the disturbances (speed of sound) in the magma. At a velocity of the order of a few meters per second, the fluid may reach the critical velocity (Mach $M=1$ ), thus choking the mass flow through the feeding system. This phenomenon may therefore explain a pressure increase at shallow depth by rising magma.

Is such a phenomenon observable? Under particular geometrical conditions, such as a conduit that undergoes sudden enlargement of its cross section, the choked fluid can reach transonic velocity (that is, mixed regions where $M<1$ and $M>1$ ). Under certain pressure regimes the flow undergoes periodic density and velocity oscillations, generating high pressure fluctuations that are transmitted to the confining rock structure. The transmitted pressure is much larger than that caused by turbulences of the moving fluid itself and can therefore be detected in the neighborhood of the volcano by means of seismometers. The basic mechanisms that lead to these high pressure oscillations are well known for gas. In a volcanological context, the modeling of a compressible two-phase flow (in this case magma with gas) as a "heavy gas" (Van Wijingaarden, 1972) and the design of corresponding identification procedures for seismic signals would permit an estimation of the pressure conditions in the magma conduits.

What lesson should be learned from this exceptional event? The lack of an adequate seismograph network and of equipment for the measurement of deformation of the volcanic structure on active volcanoes in populated areas must be viewed as an important deficiency in relation to the short-time warning problem. In the case discussed here however, it is not obvious whether information from a monitoring system could have enabled an estimation of the immediate danger. Seismological observations of earthquakes at that time were carried out by the Institut de Recherche Scientifique du Zaire by means of a short-period seismograph in Lwiro, about $100 \mathrm{~km}$ south of the volcano. Before and during the eruption, this station recorded many volcanic earthquakes, which are characterized by lowfrequency waves with dominant periods of $0.5-1.5 \mathrm{~s}$ and small P-

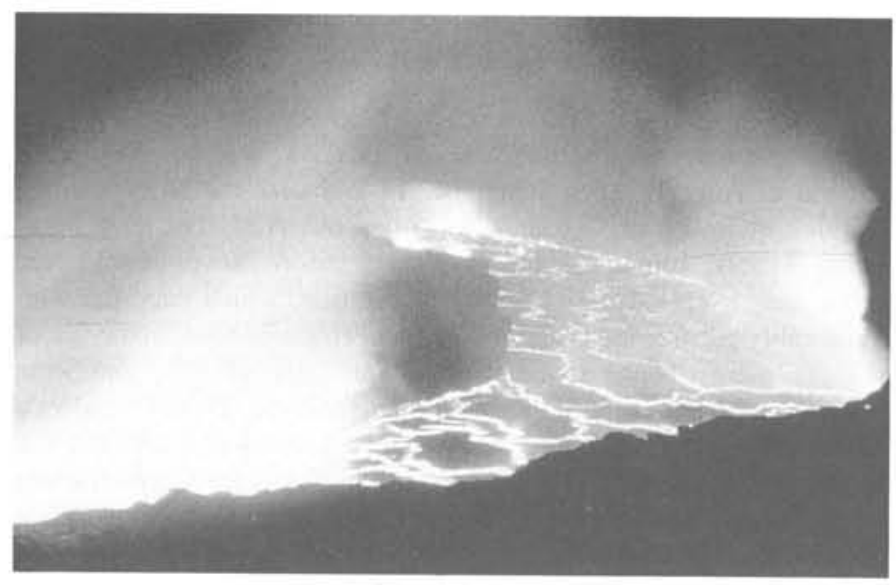

Figure 5.-Nighttime view of the lava-lake activity Nyiragongo, Zaire. The photography shows the southeastern corner of the inner pit on January 5, 1977. The lava surface is situated only few meters below the first platform.

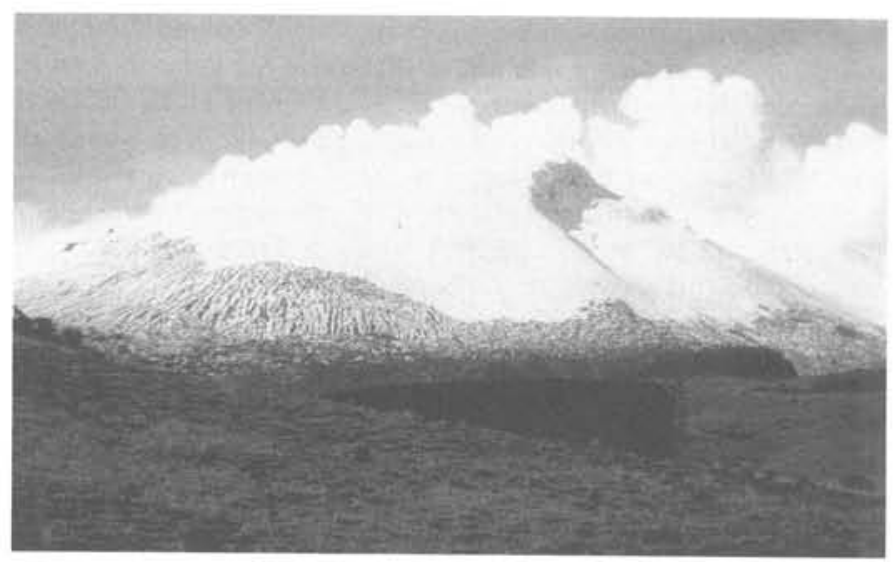

Figure 6.-Volcano Nevado del Ruiz, Colombia, on August 1985, less than three months before the catastrophic eruption of November 13. The volcano stirred to activity in late 1984 with the onset of locally felt seismicity and abnormal fumarolic activity. On November 13, 1985, descending mudflows reached and destroyed the towns Armero, Mariquita, and Chinchina, killing at least 22,000 people.

and unclear S-phases, as well as tremor, that is, seismic signals with markedly different time characteristics from that of volcanic earthquakes (Hamaguchi and others, 1982). With the help of an appropriate monitoring system, it should have been possible to locate the above mentioned earthquakes and to estimate the deformation of the volcano structure (suggested by Sahama). This would have permitted a prediction of type and main characteristics of the incumbent eruption. A time prediction for the eruptive phase would have had to have been on the basis of (1) the knowledge of the dynamic processes controlling the behavior of magma, (2) the estimation of this behavior by means of appropriate observations, and (3) consideration of mechanical properties of rocks. Current methodologies, consisting of modeling in some statistical way time relations between different phases of the eruptive activity, could have supplied the "precursors" to the eruptive phase and a corresponding time relation only after the event.

The lessons to be learned from the Nyiragongo eruption are therefore:

- Active volcanoes close to densely populated areas should be continuously monitored, even when they apparently never have been a source of immediate danger.

- Sometimes, even well-studied volcanoes can depart dangerously from "expected" usual behavior.

- Advancing in scientific understanding of the internal state preceding the eruption phase will strongly reduce the uncertainties inherent to the behavior, the short term prediction strategy for both characteristics and moment of the eruption onset should be mainly on the basis of improved knowledge about the internal behavior of the volcano. The phenomenological approach applied to unmonitored volcanoes may be too risky in emergency situations.

\section{Nevado del Ruiz}

Nevada del Ruiz (fig. 6), one of the northernmost volcanoes in Colombia, erupted on November 13, 1985, after 140 years of quiescence. The first signs of renewed activity were locally felt ground motions in late autumn 1984. On September 11, 1985, a violent 
explosion that deposited lithic blocks and lapilli around the 5,400$\mathrm{m}$-high crater, dispersed fine ash in Manizales, $25 \mathrm{~km}$ northwest of the crater. This first eruption triggered an avalanche of ice and rocks that flowed at least $27 \mathrm{~km}$ down the Azufrado River. The November 13, 1985, eruption began early in the afternoon with explosive activity and ash fall as far as $50 \mathrm{~km}$ away. No signs of the eruption that would follow were noted by a group of Colombian geologists who climbed the day before to the summit to collect gas samples. The paroxysmic phase started a few minutes after nine in the evening. Many mudflows along the rivers Azufrado, Lagunilla, and Guali destroyed houses and coffee-growing land and killed at least 22,000 people (fig. 7).

Many authors analyzed how the tragedy could have been avoided. In order to better manage similar occurrences in the future, they analyzed the multiple circumstances and events that induced the catastrophic outcome of the emergency situation (for example, Hall, 1990; Stoiber and Williams, 1990; Voight, 1990). Furthermore, numerous studies have recently treated the subjects of volcanic emergency management and of volcanic risk mitigation. Peterson (1988) focuses on the need for better flow of volcanological information between the different involved organizations in order to formulate effective emergency responses. Tilling (1989) reviewed the progress and present problems associated with studies of volcanic hazards mitigation.

Now let us analyze the state of knowledge reached in the months preceding the November 13 eruption in relation to (1) the characteristics of a possible eruption and (2) time prediction. The scenario regarded as most probable by the organizations in charge of surveillance of the volcano-INGEOMINAS (National Institute of Geology and Mines), FIDUCAL (Foundation for Improving Science and Education in the University of Caldas Province), the Volcanic Risk Committee, and the Civil Defense of Caldas province-was based on the report of Acosta (1846), who described the Ruiz eruption of February 19, 1845. In that eruption, the descending floods of water, ice, and volcanic-rock debris laid waste the whole Lagunilla valley and buried people and animals all the way to the Magdalena River, more than $100 \mathrm{~km}$ away from the volcano; these mudflows also reached the modern site of Armero. Since the September 11 activity, there was no doubt that mudflows, triggered by melting of the volcano's snowcap and threatening populated areas even in low regions, represented the most probable and dangerous consequences of increased crater activity. In the second half of September, the author ascertained, in a preliminary volcanic hazard map under preparation by INGEOMINAS and based on that used for Cotopaxi volcano in Ecuador, that mudflows were expected in all valleys issuing from the glacier. Scientists and authorities knew what could happen but not whether and when it would happen. These uncertainties played a major role in the catastrophic outcome of the November 13, 1985, eruption.

Could it have been possible to predict both the "whether" and "when" on the basis of the available geophysical observations? Before November 13, no ground-deformation equipment was installed on Ruiz, therefore the only geophysical data available for short-term prediction were the seismograms recorded by the seismographs operating around the volcano since the end of August 1985. Recorded events of volcanic seismic activity are usually divided into several categories, according to the "signature" (for example, shape, frequency content, and duration) of the signals. Available classifications, in spite of their fairly weak physical basis, allow the application of different methods of analysis. Earthquakes, long-period events, and tremor (fig. 8) are the principal categories used to classify Nevado del Ruiz seismic activity before November 13 (Munoz and others, 1990; Nieto and others, 1990).

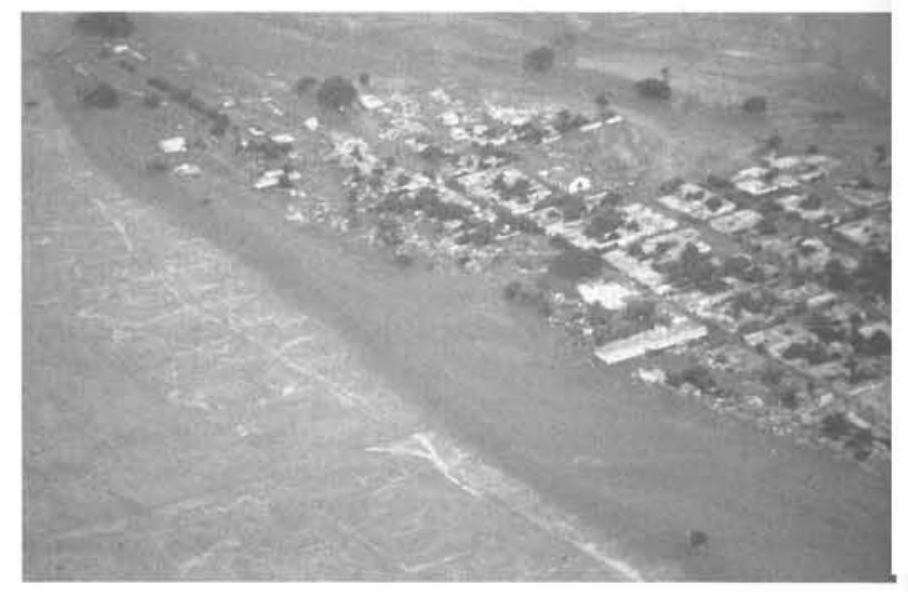

Figure 7.-The town of Armero on November 17, 1985, near Volcano Nevado del Ruiz, Colombia. Mudflows descending from the Lagunilla River have obliterated the southern half of the town, sweeping away houses (note outlines of foundations), and burying people and animals.

The recorded earthquakes were examined for their location, released energy, seismic source volume, information on local stress orientation, and seismogenetic structure. This examination leads to the identification of premonitory activity and is therefore relevant to the process of monitoring and forecasting, but only on well-studied and adequately monitored volcanoes. However, owing to the lack of earlier preeruptive experience at Nevado del Ruiz, no premonitory activity, relevant for short-term prediction, could have been and can be found by means of earthquake analysis.

The class of long-period events includes a wide range of volcanic seismograms characterized by low frequency content $(<4 \mathrm{~Hz})$ and short duration (less than $1 \mathrm{~min}$ ). Their occurrence reflects a particular dynamical behavior of fluids (magma or water) at depth and therefore, the knowledge of the mechanisms leading to such signals is of interest in short-term prediction problems. The daily number of long-period events does not show significant changes immediately before the September 11 and the November 13 eruptions. Only after both these eruption phases, can an increase of this seismic activity be observed (Nieto and others, 1990). Therefore, the daily quantity of long-period events is in this case not relevant for short-term prediction.

Tremor that was characterized by continuous seismic energy release and that lasted minutes, hours, or days, was observed since the end of August. After September 11 and until the November 13 eruption, more intensive tremor was often observed. The most interesting signals, among the ones collected before November 13, are cyclic tremor episodes of 15-20 min duration, which occurred with remarkably regular intervals of $1-1.5 \mathrm{~h}$. These periodic intervals of seismic energy began to be recorded on September 5, and were observed until the eruption phase of September 11. Figure 9 shows a record of this type of activity, recorded at a distance of $4 \mathrm{~km}$ from the crater, on September 7. There is a striking similarity between this phenomenon and cyclic tremor observed at Karkak Volcano in Papua New Guinea (McKee and others, 1981). As for Nevado del Ruiz, this type of episodic tremor signal has been observed to be followed there by explosions in the crater. This correspondence shows that cyclic tremor signals (independent of the knowledge about the mechanisms generating them) may still be useful for the forecasting of eruptions. Bands of tremors were observed at the Nevado del Ruiz a few days 


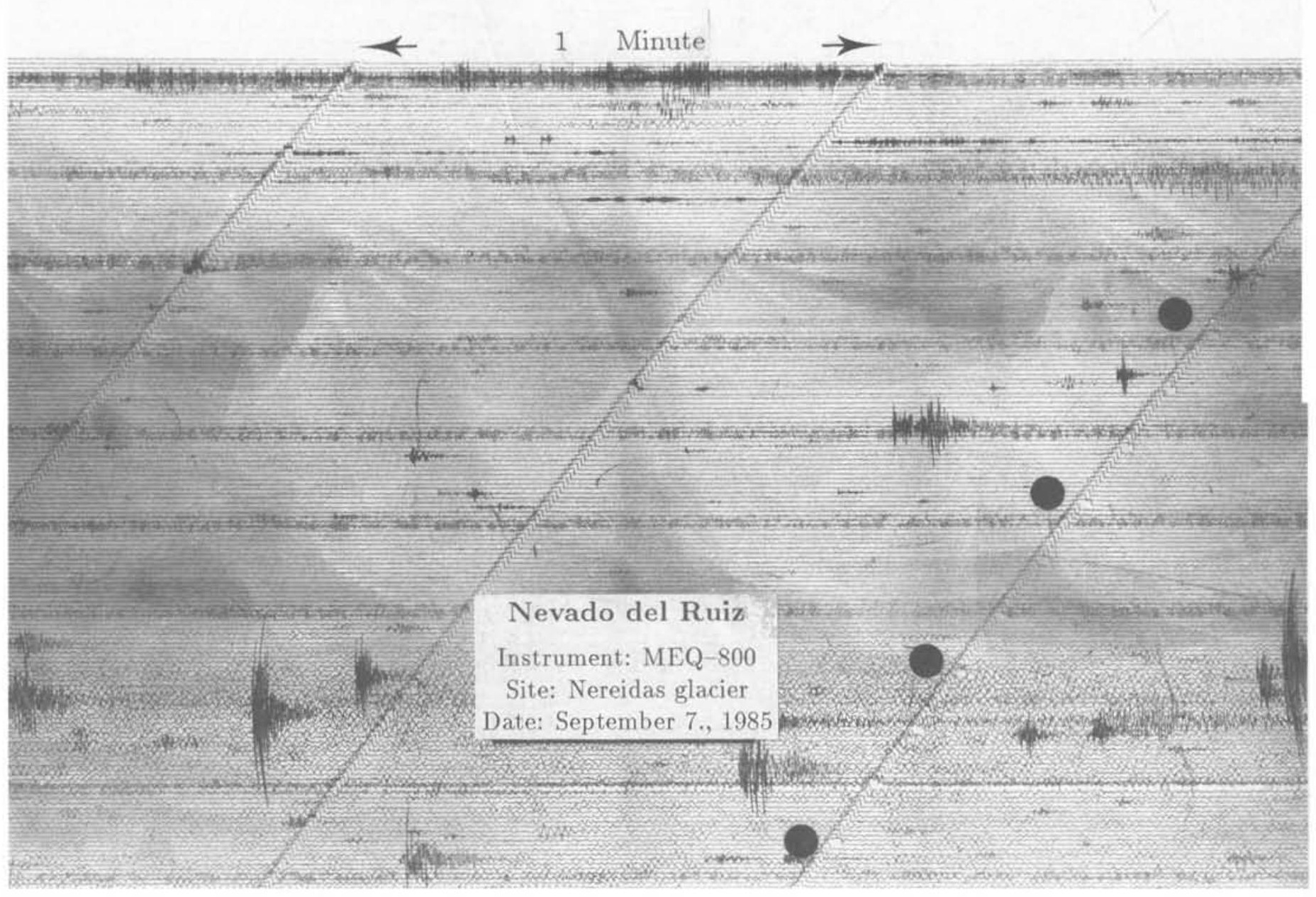

Figure 9.-Volcano Nevado del Ruiz, Colombia. Seismogram showing cyclic tremor episodes on September 7, 1985, at a station located about $4 \mathrm{~km}$ southwest of the crater. The duration of each episode is 15-20 minutes. This activity began on September 5 , 1985, and disappeared after the phreatic eruption of September 11.

factor for the achievement of the above proposed goals. However, current methodologies for prediction are based on modeling procedures in which the model is obtained almost solely from the observed data. As such, the modeling is dominated by a statistical approach that is very restrictive in a volcanological context. In the opinion of the author, the much too central role played by statistics in the analysis of geophysical data is the main reason for the lack of efficient methods for predicting volcanic eruption. That which is unknown must not be equated with that which is random, and therefore, physics and not statistics is the necessary tool for investigation.

In addition, particular attention has to be paid to the problem of finding dynamic models from observed time series. In system-theory, this is usually referred to as the identification problem.

Certainly, seismology offers the most effective means to investigate dynamic processes related to the state of a volcano. A lot of volcanic seismic signals are triggered by mechanisms of fluid dynamics, therefore, the investigation of the related identification problems as well as the estimation of the involved parameters will supply the knowledge necessary for the design of short-term prediction procedures. Processes leading to strong vibrations of the fluid conduits must be investigated and classified in relation to the characteristics of the vibrations. The investigation must cover both theoretical and experimental work.

It should be emphasized that real progress in the field can only be reached if one succeeds in involving other domains of volcanology in the interpretation of seismic signals. Significant contributions should be gained from geochemistry and petrology in addition to the classical geophysical methods, such as gravimetry and geodesy.

Research on seismic signals should therefore be viewed as a multidisciplinary subject, if short-term prediction methods are to be based on the understanding of the internal state of the volcano.

\section{References}

Acosta, J., 1846, Relation de l'eruption bouese sortie du volcan de Ruiz, et de la catastrophe de Lagunilla dans la republique de la NouvelleGrenade, C.R. Acad. Sci,, Paris, XXIL.

Hall, M.L., 1990, Chronology of the principal scientific and governmental actions leading up to the November 13, 1985 eruption of Nevado del Ruiz, Colombia: Journal of Volcanology and Geothermal Research, v. 42. p. $101-116$ 
Hamaguchi, H., Zana, D., Tanaka, K., Kasahara, M., Mishina, M., Ueki, S., Sawa-sawa, K., and Tachibana, K., 1982, Observations of volcanic earthquakes and tremors at volcanoes Nyiragongo and Nyamuragira in the Western Rift Valley of Africa: Tohoku Geophysical Journal Volume 29 , no. 1, p. 41-56.

McKee, C.O., Wallance, D.A., Almond, R.A., and Talai, B., 1981, Fatal hydro-eruption of Karkar volcano in 1979-development of a maar-like crater, in Johnson, R.W., ed., Cookre-Ravian Volume of Volcanological Papers: Geological Survey of Papua New Guinea, Memoir 10, p. 63-84.

Munoz, F., 1990, Analysis of swarms of high-frequency seismic events at Nevado del Ruiz volcano, Colombia (January 1986-August 1987)-Development of a procedure: Journal of Volcanology and Geothermal Research, v. 41 , p. $327-354$.

Nieto, A.H., Brandsdottir, B., and Munoz, F., 1990, Seismicity associated with the reactivation of Nevado del Ruiz, Colombia, July 1986December 1986: Journal of Volcanology and Geothermal Research, v. 41, p. 315-326.

Peterson, D.W., 1988, Volcanic Hazards and Public Response: Journal of Geophysical Research, v. 93, no. B5, p. 4161-4170.

Sparks, R.S.J., 1978, The dynamics of bubble formation and growth in magma $-A$ review and analysis: Journal of Volcanolgy and Geothermal Research, v. 3, p. 1-37.

Stoiber, R.E., and Williams, S.N., 1990, The 1985 Nevado del Ruiz volcano catastrophe-Anatomy and retrospection: Journal of Volcanology and Geothermal Research, v. 42, p. 129-150.

Stuhlmann, Franz, 1894, Mit Emin Pascha ins Herz von Afrika: Berlin, D. Reimer, $901 \mathrm{p}$.

Tazieff, H., 1949, Premiere exploration du volcan Niragongo: Bull. Soc. belge Geol. LVIII, p. 165-172.

1977, An Exceptional Eruption-Mt. Niragongo, January 10, 1977; Bulletin of Volcanology, v. 40-3.

-1985, Recent Activity at Nyiragongo and Lava-Lake Occurrences: Geological Society of Finland Bulletin, 57, p. 11-19

Tilling R., 1989, Volcanic Hazards and their Mitigation-Progress and problems: Reviews of Geophysics v. 27, no. 2, p. 237-269.
Van Wijingaarden, L., 1972, One-dimensional flow of liquids containing small gas bubbles: Annual Review of Fluid Mech. v. 4, p. 369-396.

Voight, B., 1990, The 1985 Nevado del Ruiz volcano catastropheAnatomy and retrospection: Journal of Volcanology and Geothermal Research, v. 42 , p. $151-188$.

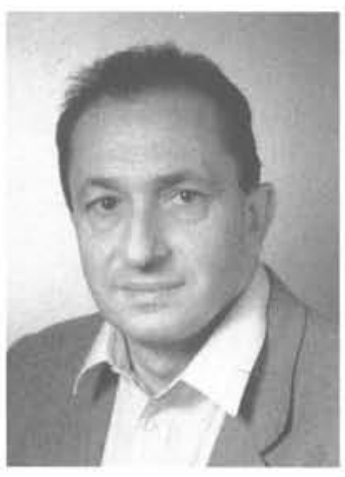

Dr. Bruno Martinelli was born in 1940 in Chiasso, Switzerland. After receiving his degree in theoretical physics in 1969 from the ETH, Zurich, he spent three years in Rwanda (Africa) as an expert of the Swiss Technical Aid, teaching mathematics and physics. From 1973 to 1984. Martinelli worked as a mathematical system theorist at an electronics company in Zurich and was mainly involved in subjects related to estimation and control problems. After the 1977 Mount Nyiragongo eruption. observed by the author from the nearby town of Gysenyi, his main research interest has been physical volcanology. Martinelli received his Ph.D. at the ETH, Zurich, in 1991 with the thesis "Fluid induced source mechanisms for volcanic tremor." Since 1988, he has been a research scientist at the Swiss Seismological Service, Institute of Geophysics, ETH, Zurich, Switzerland. 